\title{
CONTROLLED LIMB REPERFUSION IN PATIENTS HAVING CARDIAC OPERATIONS
}

Friedhelm Beyersdorf, $\mathrm{MD}^{\mathrm{a}}$

Zan Mitrev, MD*

Kai Ihnken, MD

Walther Schmiedt, $\mathrm{MD}^{\mathrm{b}}$

Koppany Sarai, MD

Lothar Eckel, $\mathrm{MD}^{\mathrm{a}}$

Ortwin Friesewinkel, MD ${ }^{\mathrm{c}}$

Georg Matheis, $\mathrm{MD}^{\mathrm{a}}$

Gerald D. Buckberg, MD
Hypothesis: Severe limb ischemia in patients having cardiac operations may occur after intraaortic balloon pump insertion, prolonged femoral vessel cannulation, percutaneous cardiopulmonary bypass, dissecting aneurysms, or emboli. Normal blood reperfusion can cause a postischemic syndrome that increases morbidity and mortality. This clinical study is based on an experimental infrastructure patterned after controlled cardiac reperfusion. (1) It tests the hypothesis that controlled limb reperfusion (i.e., modifying the composition of the initial reperfusate and the conditions of reperfusion) reduces the local and systemic complications seen after normal blood reperfusion. (2) It reports initial clinical application of this strategy in three cardiac surgery centers. Methods: Controlled limb reperfusion was applied to 19 patients with signs of severe prolonged unilateral or bilateral ischemia (including paralysis, anesthesia, and muscle contracture); six patients (32\%) were in cardiogenic shock. The mean ischemic duration was $26 \pm 6$ hours. The reperfusion method includes a 30-minute infusion into the distal vessels of a normothermic reperfusate solution mixed with the patient's arterial blood (obtained proximal to the obstruction) in a 6:1 blood/reperfusate ratio. Data are mean \pm standard error of the mean. Results: Sixteen patients $(84 \%)$ survived with salvaged and functional limbs at the time of discharge. No renal, cardiac, pulmonary, cerebral, or hemodynamic complications developed in the survivors. The three deaths occurred in patients undergoing controlled limb reperfusion while in profound postoperative cardiogenic shock; neither postischemic edema nor contracture developed in any of them. Conclusions: These findings show that controlled limb reperfusion can be applied readily with standard equipment that is used for cardiac surgery and may salvage limbs while reducing postreperfusion morbidity and mortality. (J THORAC CARDIOVASC SURG 1996;111:873-81)
Severe limb ischemia in patients having cardiac operations may occur after (1) transfemoral insertion of an intraaortic balloon pump (IABP), (2)

From the Department of Thoracic and Cardiovascular Surgery, Johann Wolfgang Goethe-University Frankfurt/M., ${ }^{a}$ Department of Cardiothoracic and Vascular Surgery, Johannes Gutenberg-University Mainz, ${ }^{b}$ and Department of Thoracic and Cardiovascular Surgery, German Heart Center, Berlin, Germany. ${ }^{c}$

Dr. Mitrev was supported by a grant from the MC-Stip and the German Heart Foundation.

Received for publication Jan. 9, 1995; accepted for publication June 27, 1995.

Address for reprints: Friedhelm Beyersdorf, MD, Department of Cardiovascular Surgery, Albert-Ludwigs-University Freiburg, Hugstetterstr. 55, 79106 Freiburg, Germany.

*Visiting fellow from the Department of Thoracic and Cardiovascular Surgery, "Sv. Kiril i Metodi" University of Skopje, Macedonia.

Copyright (C) 1996 by Mosby-Year Book, Inc.

$0022-5223 / 96 \$ 5.00+0 \quad \mathbf{1 2 / 1 / 6 7 5 0 7}$ prolonged femoral vessel cannulation (i.e., thoracic aortic aneurysms, reoperations), (3) thoracoabdominal acute aortic dissections, (4) prolonged percutaneous cardiopulmonary bypass, (5) thrombosis during or after removal of coronary angiography catheters into atherosclerotic vessels, or (6) thromboembolization.

Reperfusion of these severely ischemic limbs with normal blood may result in a postischemic syndrome that is associated with high mortality and morbidity rates. ${ }^{1}$ The massive edema can increase fluid requirements and cause shock. Additionally, the washout of myoglobin, potassium, lactate, and microthrombi from the damaged skeletal muscle into the systemic circulation may cause renal failure, arrhythmias, shock, and eventually death ${ }^{1-3}$ inasmuch as mortality rates vary from $7.5 \%$ to $41 \% .^{1,2} \mathrm{~A}$ postreperfusion syndrome may result in amputation or severe dysfunction in the salvaged limbs. ${ }^{1,2}$ Our 
Table I. Composition of the asanguineous solution for the controlled limb reperfusate* (to be mixed with blood at a ratio of 6 to $1^{\dagger}$ )

\begin{tabular}{lcl}
\hline \multicolumn{1}{c}{ Substance } & $\begin{array}{c}\text { Amount } \\
(\mathrm{ml})\end{array}$ & \multicolumn{1}{c}{ Principle } \\
\hline Glucose 5\% & 500 & $\begin{array}{l}\text { Hyperosmolarity } \\
\text { Substrate }\end{array}$ \\
Citrate-phosphate-dextrose & 150 & Reduce $\mathrm{Ca}^{++}$ \\
Tromethamine $0.3 \mathrm{ml} / \mathrm{L}$ & 200 & Buffer \\
Glutamate/aspartate & 150 & Substrate \\
Allopurinol & 2.5 & Free radical scavenger
\end{tabular}

*Manufactured by Dr. F. Köhler Chemie GmbH-Hähnlein, Germany.

${ }^{+}$Six parts blood and one part asanguineous solution.

recent experimental studies ${ }^{4-10}$ and those of others ${ }^{11-14}$ show that this injury can be reduced substantially by modifying the initial reperfusion phase during surgical revascularization of severely ischemic skeletal muscle. The concept of controlled limb reperfusion $^{4-10}$ is based on principles described for cardiac reperfusion in patients with acute myocardial infarctions ${ }^{15-18}$ or after aortic clamping. ${ }^{19-21}$ This new application to ischemic skeletal muscle incorporates modifications of the conditions of reperfusion (temperature, pressure, and flow) and the composition of the reperfusate (oxygen tension, hematocrit value, free radical scavengers, osmolarity, calcium, $\mathrm{pH}$, substrates, and glucose) during the first 30 minutes of regional revascularization. It also limits the local and systemic adverse effects of reperfusion after prolonged limb ischemia.

The initial experience with clinical application of this method in 19 patients at three university cardiac surgical centers is summarized, and the results suggest that limb salvage is possible in extremities thought previously to be damaged irreversibly because of ischemic contracture.

\section{Material and methods}

Patient population. Controlled limb reperfusion was performed in 19 patients with completely ischemic limbs at the Johann Wolfgang Goethe-University Frankfurt/M. $(n=15)$, Johannes Gutenberg-University Mainz $(n=3)$, and German Heart Center Berlin $(n=1)$. The design of the study was approved by the ethics committee. The onset of acute limb ischemia was defined as the time of pain as reported by the patient or the diagnosis made by the referring physician. Acute lower limb ischemia was confirmed by history, physical examination, and Doppler sonographic examination. Angiograms were not performed routinely in the preoperative period.

Initial signs and symptoms, length of time from sudden occlusion to start of reperfusion, severity of ischemia, associated disease, source and location of thrombi or emboli, type of surgical intervention, and outcome of surgery were registered and are described in the Results section.

Surgical technique for controlled limb reperfusion. Fluid, electrolytes, and cardiovascular abnormalities were corrected as much as possible before the operation. All patients received a standard heparin dose $(300 \mathrm{IU} / \mathrm{kg})$ after induction of general anesthesia. Central venous and urinary catheters were introduced, and blood pressure, heart rate, and electrocardiogram were monitored continuously. Fluid replacement was restricted to account for the crystalloid load infused with the controlled reperfusate, and furosemide (10 mg) was given intravenously, as needed.

The common, superficial, and deep femoral arteries were exposed and isolated by a standard groin incision. A common femoral longitudinal arteriotomy was made just above the bifurcation, and all thromboembolic material was removed from the iliac, superficial, and femoral arteries with a Fogarty catheter. The distal vessel was not irrigated. A wire-reinforced $22 \mathrm{~F}$ cannula was inserted into the iliac artery via the same arteriotomy to aspirate autogenous oxygenated blood for subsequent admixture with the reperfusate solution (Table I). This cannula was connected to the blood line (Fig. 1) of the reperfusion set (HP Medica, Augsburg, Germany), which also contained a smaller caliber tubing for delivery of asanguineous solution. Both tubing lines were inserted into the head of a single roller pump, thereby permitting delivery of oxygenated autogenous blood and reperfusate solution (Dr. F. Köhler Chemie GmbH, Alsbach-Hähnlein, Germany) at a ratio of 6 to 1 (6 parts blood and 1 part asanguineous solution) to achieve the composition described in Table II.

The lines were connected with a Y connector beyond the pump, and the modified blood reperfusate solution was channeled through a heat exchanger and an arterial filter. An additional $\mathrm{Y}$ connector was added to the delivery line for connection of two reperfusion cannulas to be inserted into the superficial and deep femoral arteries. These vessels were each cannulated with a $10 \mathrm{~F}$ duallumen catheter with self-inflating balloons (Research Medical Inc., Salt Lake City, Utah) to allow individual pressure measurement during reperfusion. The system was deaired before cannulation of the superficial and deep femoral arteries. Controlled reperfusion flow rate was adjusted by the roller pump at 150 to $250 \mathrm{ml} / \mathrm{min}$. A tubing clamp on each perfusion line was used to change resistance, as needed, to ensure that intravascular pressure in each vessel never exceeded $60 \mathrm{~mm} \mathrm{Hg}$.

Suturing of the venous patch with 5-0 monofilament suture to close the longitudinal arteriotomy was started during the 30-minute limb reperfusion interval. The cannulas were then removed and the patch anastomosis completed to restore normal blood supply. Arterial systolic pressure was kept below $120 \mathrm{~mm} \mathrm{Hg}$ with systemic vasodilators within the first 24 hours after the operation. Systemic heparin was continued for 2 days to keep activated clotting time at 150 seconds, and conversion to warfarin sodium was undertaken whenever a source of embolism (i.e., cardiac) was documented.

Statistical analysis. Statistical analysis was done with the EPISTAT and the BIAS computer package provided by the Johann Wolfgang Goethe-University Frankfurt/ 
Table II. Final composition of the controlled limb reperfusate (after mixing with blood in a ratio of

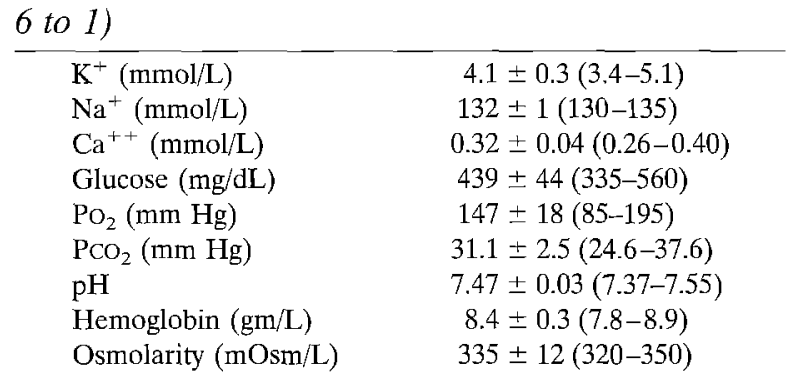

Data are mean \pm standard error of the mean (range). $\mathrm{PO}_{2}$, Oxygen tension; $P_{\mathrm{CO}_{2}}$, carbon dioxide tension.

Table III. Preoperative data $(n=19)$

\begin{tabular}{lc}
\hline Age (yr) & $56 \pm 4$ \\
Male/female & $14 / 5$ \\
Site of occlusion & \\
Infrarenal aorta & $3 / 19$ \\
Iliac artery & $4 / 19$ \\
Femoral artery & $10 / 19$ \\
Popliteal artery & $2 / 19$ \\
Complete/incomplete ischemia & $18 / 1$ \\
Cardiogenic shock & $32 \%(6 / 19)$ \\
Muscle contracture (thigh or shank) & $53 \%(10 / 19)$ \\
Duration of ischemia (hr) & $26 \pm 6$ \\
\hline
\end{tabular}

Data are mean \pm standard error of the mean.

M., Germany, in conjunction with Dr. H. Ackermann, a biomathematician (Johann Wolfgang Goethe-University Frankfurt/M., Germany). Comparisons between groups were done with the one-way analysis of variance and nominal data by Fisher's exact test. Data are expressed as mean \pm standard error of the mean. Differences were considered significant at a $p$ value less than 0.05 .

\section{Results}

Preoperative data. Patients' ages ranged from 19 to 83 years (Table III). Fourteen patients were male and five female. Of these, six patients (32\%) were in cardiogenic shock requiring both inotropic support and intraaortic balloon counterpulsation. The femoral artery was the site of vascular occlusion in 16 patients; three patients had acute infrarenal aortic occlusion with subsequent bilateral femoral artery occlusion. The mean ischemic interval averaged 26 hours (range 6 to 39 hours). All limbs were pulseless, pale, and paralyzed, and patients who were not intubated complained of pain and paresthesia. Muscle contracture of the thigh or shank occurred in 10 of 19 patients $(53 \%)$. The decision to offer controlled limb reperfusion was based on (1) clinical concern that severe postischemic syndrome would

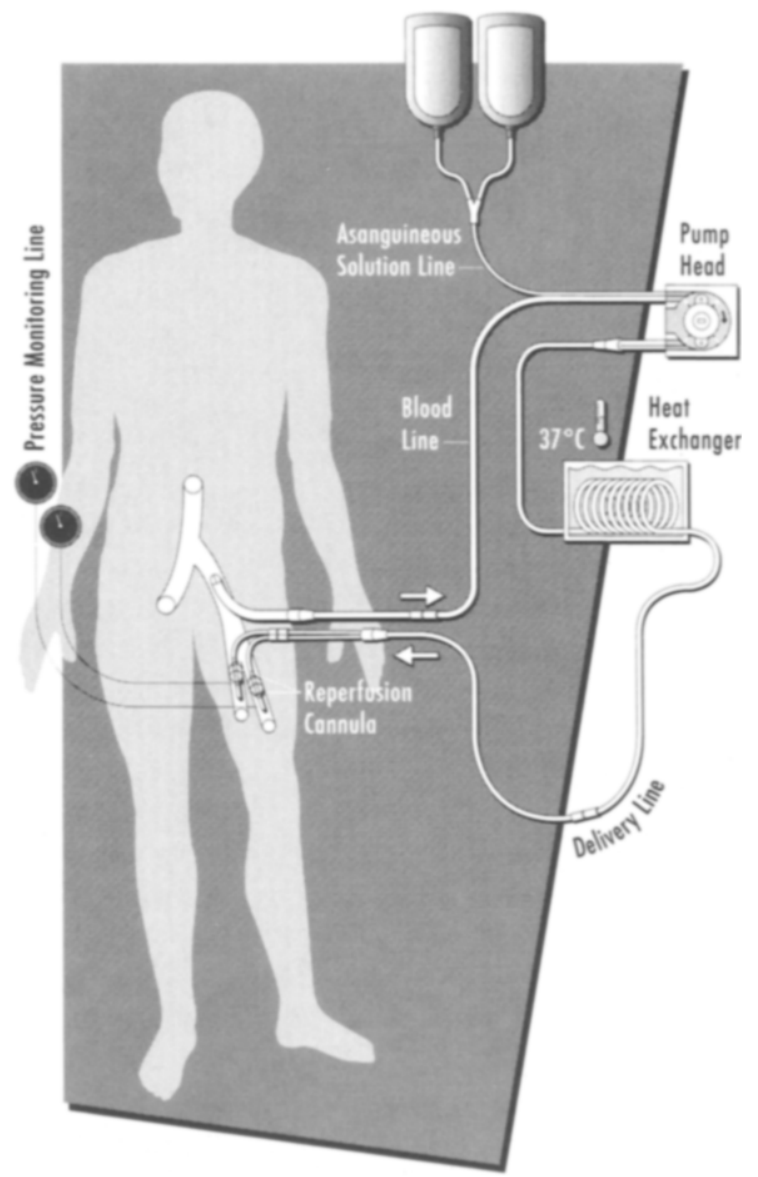

Fig. 1. Schematic representation of the clinical reperfusion set for controlled limb reperfusion. The iliac artery is cannulated to withdraw autogenous oxygenated blood from the patient. This blood is mixed with an asanguineous solution at a ratio of $6: 1$, administered at normothermia $\left(37^{\circ} \mathrm{C}\right)$ through the heat exchanger, and delivered into the superficial and deep femoral arteries while intraarterial pressures are being monitored.

follow normal blood reperfusion or (2) the fear that primary amputation would be necessary because of contracture.

Intraoperative data. The external iliac artery and the superficial and deep femoral arteries could be cannulated via the longitudinal arteriotomy after thrombectomy in 18 of 19 patients. Iliac artery thromboendarterectomy was needed in one patient to allow proximal cannulation. Systolic blood pressure fell slightly while the reperfusion system was primed with the patient's autologous oxygenated blood, and this was reversed after controlled reperfusion was initiated. Systemic blood pressure, central venous pressure, systemic vascular resistance, 
Table IV. Arteriovenous difference of electrolytes, glucose, $\mathrm{PO}_{2}, \mathrm{PCO}_{2}$, and $\mathrm{pH}$ during controlled limb reperfusion in patients

\begin{tabular}{|c|c|c|c|c|}
\hline & \multicolumn{4}{|c|}{ Duration of controlled limb reperfusion } \\
\hline & $1 \min$ & 5 min & $15 \mathrm{~min}$ & $30 \mathrm{~min}$ \\
\hline \multicolumn{5}{|l|}{ Electrolytes } \\
\hline $\mathrm{K}^{+}(\mathrm{mmol} / \mathrm{L})$ & $0.2 \pm 0.8$ & $-0.6 \pm 0.1$ & $-1.2 \pm 0.1$ & $-0.9 \pm 0.3$ \\
\hline $\mathrm{Na}^{+}(\mathrm{mmol} / \mathrm{L})$ & $-2 \pm 2$ & $-3 \pm 1$ & $-3 \pm 1$ & $-3 \pm 1$ \\
\hline $\mathrm{Ca}^{++}(\mathrm{mmol} / \mathrm{L})$ & $-0.5 \pm 0.3$ & $-0.4 \pm 0.2$ & $-0.4 \pm 0.2$ & $-0.4 \pm 0.2$ \\
\hline Glucose $(\mathrm{mg} / \mathrm{dl})$ & $74 \pm 37$ & $143 \pm 66$ & $165 \pm 59$ & $186 \pm 53$ \\
\hline \multicolumn{5}{|l|}{ Blood gases } \\
\hline $\mathrm{PO}_{2}(\mathrm{~mm} \mathrm{Hg})$ & $113 \pm 22$ & $127 \pm 26$ & $99 \pm 23$ & $94 \pm 19$ \\
\hline $\mathrm{PCO}_{2}(\mathrm{~mm} \mathrm{Hg})$ & $-16 \pm 4$ & $-13 \pm 2$ & $-18 \pm 3$ & $-13 \pm 3$ \\
\hline $\mathrm{pH}$ & $0.12 \pm 0.02$ & $0.06 \pm 0.05$ & $0.14 \pm 0.02$ & $0.11 \pm 0.02$ \\
\hline
\end{tabular}

Data are mean \pm standard error of the mean.

Table V. Maximal postoperative serum values for enzymes, creatinine, blood urea nitrogen, and potassium

$\begin{array}{lc}\text { Enzymes } & \\ \text { CK }(\mathrm{U} / \mathrm{L}) & 20,414 \pm 7,710 \\ \text { AST }(\mathrm{U} / \mathrm{L}) & 455 \pm 184 \\ \text { LDH (U/L) } & 1,356 \pm 540 \\ \text { Renal data } & \\ \quad \text { creatinine (mg/dl) } & 2.4 \pm 0.7 \\ \text { BUN (mg/dl) } & 65 \pm 8 \\ \text { Electrolytes } & \\ \mathrm{K}^{+}(\mathrm{mmol} / \mathrm{L}) & 5.3 \pm 0.5\end{array}$

Data are mean \pm standard error of the mean. $C K$. Creatine kinase; $A S T$, aspartate aminotransferase; $L D H$, lactic dehydrogenase; $B U N$, blood urea nitrogen; $K^{+}$, potassium.

heart rate, and urine output did not change, and each patient received approximately $800 \mathrm{ml}$ of crystalloid solution (range 214 to $1285 \mathrm{ml}$ ) as the $6: 1$ blood/reperfusate solution was delivered. Reperfusion rates averaged 150 to $250 \mathrm{ml} / \mathrm{min}$ (range 50 to $300 \mathrm{ml} / \mathrm{min}$ ) to keep intravascular pressure between 50 and $60 \mathrm{~mm} \mathrm{Hg}$. Normal arterial inflow was restored by vein patch closure of the arteriotomy after decannulation.

Twelve of 19 patients underwent fasciotomy, which was performed prophylactically in the initial patients because severe limb edema was expected. Our early experience showed that most fasciotomies were unnecessary; therefore this was done subsequently only if severe limb swelling followed revascularization.

Intraoperative metabolic data (Table IV). Minimum and significant changes in serum, potassium, sodium, and calcium concentrations occurred during the 30-minute period of controlled limb reperfusion, and severe hyperkalemia $(>2 \mathrm{mEq} / \mathrm{L}$ increase in serum $\mathrm{K}^{+}$) never occurred. In contrast, glucose uptake rose progressively during the period of regional limb reperfusion, as arteriovenous glucose difference exceeded $140 \mathrm{mg} / \mathrm{dl}$ after 5 minutes. Substantial oxygen extraction occurred throughout the entire controlled reperfusion period, as arteriovenous oxygen difference ranged between 94 and $127 \mathrm{~mm} \mathrm{Hg}$. Effluent femoral vein $\mathrm{pH}$ remained in the normal range of 7.3 to 7.4 , even though carbon dioxide is released into the venous circulation.

Postoperative systemic alterations. Table V shows maximum values for serum, potassium, creatinine, and blood urea nitrogen. Massive creatine kinase (CK) release occurred in all patients, but the increase in $\mathrm{K}^{+}$, creatinine, and blood urea nitrogen was negligible. The average postoperative fluid requirements were $30 \mathrm{ml} / \mathrm{kg}$ for the first 24 hours.

Postoperative clinical data. Sixteen of 19 patients survived (84\%), with deaths occurring in three of six patients undergoing controlled limb reperfusion during cardiogenic shock. No systemic postoperative complications occurred in survivors, inasmuch as none required hemodialysis, had rhythm disturbances, or had lung changes. All fasciotomies but one were closed between the fourth and eighth postoperative days. Each of the 16 survivors had full sensory and motor functional recovery of both limbs at the time of discharge as assessed by the discharging surgeon.

Only one death was associated with the reperfusion process. Progressive congestive heart failure and multisystem organ failure developed in a patient with cardiogenic shock who had acute distal aortic occlusion. A second death was due to irreversible low output syndrome, and the third death was due to cerebral hypoxia and sepsis in a patient who underwent acute coronary revascularization after arriving in the operating room while undergoing cardiopulmonary resuscitation. 
Table VI. Clinical results after thromboembolectomy for acute arterial occlusion in 2392 patients

\begin{tabular}{|c|c|c|c|c|c|c|}
\hline Reference & $\begin{array}{c}\text { No. of } \\
\text { patients }\end{array}$ & Ischemic time & $\begin{array}{c}\text { Mortality } \\
(\%)\end{array}$ & $\begin{array}{c}\text { Amputation } \\
(\%)\end{array}$ & $\begin{array}{c}\text { Nonfunctional } \\
\text { (\%) }\end{array}$ & Mean age \\
\hline 1 & 17 & $1 \mathrm{hr}-7$ days & 11.8 & 23.5 & 17.6 & $59 \mathrm{yr}$ \\
\hline 53 & 94 & 1-21 days & 13.7 & 5.4 & No data & $72.8 \mathrm{yr}$ \\
\hline 54 & 246 & $1 \mathrm{hr}-42$ days & 29.7 & 5.3 & 9.8 & 62 уг \\
\hline 55 & 142 & $1 \mathrm{hr}-30$ days & 28 & 9 & No data & No data \\
\hline 56 & 224 & No data & 23.1 & 9 & No data & $63 \mathrm{yr}$ \\
\hline 57 & 118 & No data & 19.5 & 31 & No data & No data \\
\hline 58 & 91 & $1 \mathrm{hr}-8$ days & 34 & 11 & No data & $77 \mathrm{yr}$ \\
\hline 2 & 85 & $1 \mathrm{hr}-7$ days & 41 & 40 & No data & No data \\
\hline 59 & 124 & $1 \mathrm{hr}-?$ & 30 & 22 & No data & No data \\
\hline 60 & 100 & $1 \mathrm{hr}-30$ days & 26 & 10 & No data & $67 \mathrm{yr}$ \\
\hline 61 & 128 & No data & 34 & 5 & No data & $68 \mathrm{yr}$ \\
\hline 62 & 125 & $1 \mathrm{hr}-24 \mathrm{hr}$ & 25.6 & & No data & No data \\
\hline 63 & 119 & $1 \mathrm{hr}->8$ days & 27 & 18 & No data & No data \\
\hline 64 & 142 & $1 \mathrm{hr}->24 \mathrm{hr}$ & 27 & 8.5 & No data & $65.5 \mathrm{yr}$ \\
\hline 65 & 66 & $1 \mathrm{hr} \rightarrow>24 \mathrm{hr}$ & 34.8 & 6.1 & No data & No data \\
\hline 66 & 65 & $1 \mathrm{hr}->12 \mathrm{hr}$ & 48 & 12 & No data & No data \\
\hline 67 & 122 & $1 \mathrm{hr}-48 \mathrm{hr}$ & 10.6 & 11.5 & 8 & No data \\
\hline 68 & 221 & No data & 37 & 27 & No data & $77 \mathrm{yr}$ \\
\hline 69 & 163 & No data & 14.7 & 8 & 16 & $62.5 \mathrm{yr}$ \\
\hline
\end{tabular}

\section{Discussion}

Limb ischemia in patients who have had cardiac operations is an infrequent but life-threatening complication that occurs most commonly after prolonged transfemoral intraaortic balloon counterpulsation. The reported prevalence varies between $9 \%$ and $12 \%,{ }^{22-27}$ and amputation is needed in $1 \%$ of patients. ${ }^{28}$ Limb ischemia after insertion of an IABP is due to either flow obstruction by the cannula or mechanical vessel wall trauma during insertion and is accentuated by the intense vasoconstriction that accompanies the low cardiac output in these patients. $^{29-31}$ Ischemic limb complications are more common in patients with preexisting arterial occlusive disease, ${ }^{32}$ in women $^{33,34}$ because of their smaller caliber vessels, and in patients in whom larger IABP catheters are used. ${ }^{35}$ Recommended prophylactic measures include transaortic IABP insertion, ${ }^{36,37}$ use of shunt sheaths with side holes, ${ }^{38}$ sheathless IABP insertion, ${ }^{39,40}$ iliac artery balloon angioplasty if the vessel is stenotic, ${ }^{41}$ and papaverine treatment. ${ }^{42}$ Unfortunately, limb ischemia remains the major complication after transfemoral IABP insertion despite these efforts. Additional causes of limb ischemia include acute dissecting aneurysms, presence of aortoiliac disease in patients who undergo percutaneous femoral arterial cannulation for instituting cardiopulmonary bypass for emergency cardiac operations, ${ }^{43,44}$ or circulatory support during angioplasty. ${ }^{45}$

The mortality rate after primary amputation for acute limb ischemia is approximately $1 \%$, whereas mortality increases to approximately $20 \%$ to $30 \%$ (range $10.6 \%$ to $48 \%$ ) after revascularization (Table VI). Reperfusion injury of tissue jeopardized by the preceding ischemic period is the principal cause for increased morbidity and mortality after acute limb revascularization. ${ }^{3,4}$ Skeletal muscle has been shown to be relatively intact biochemically and structurally even after prolonged periods of ischemia, ${ }^{6,46}$ yet several experimental and clinical reports indicate that sudden restoration of normal blood flow supply may cause severe edema, rhabdomyolysis, and leakage of myocyte content into the plasma. ${ }^{46-48}$ The resultant massive washout of lactate, potassium, and myoglobin may produce lifethreatening myoglobinuric renal failure, hyperkalemia, disseminated intravascular coagulation, and acute cardiomyopathy. ${ }^{1,2,49}$

$\mathrm{We}^{4-10}$ have demonstrated experimentally that local and systemic complications after normal blood reperfusion can be reduced significantly if the vulnerable skeletal muscle is managed during the first 30 minutes of restoration of its blood supply by the controlled limb reperfusion strategy. Using a model of acute infrarenal aortic occlusion for 6 hours, we $e^{6,10}$ developed evidence that uncontrolled normal blood reperfusion produced by suddenly releasing the aortic occlusion reduced oxygen consumption, produced marked edema and massive $\mathrm{CK}$ and potassium release, and increased vascular resistance severely, causing low reflow. The result was decreased recovery of range of motion of 
the knee joint. Biopsy of the jeopardized muscle before reperfusion and evaluation of the tissue with an electron microscope showed structural integrity, ${ }^{6}$ and this observation emphasized the importance of developing a reperfusion method that could limit injury to skeletal muscle jeopardized by ischemia otherwise destined for necrosis. These adverse effects of normal blood reperfusion were relatively comparable with those after normal blood reperfusion in ischemic cardiac myocytes. Our management strategy is based on the salutary effects shown when controlled reperfusion was provided to cardiac muscle after regional and global ischemia. ${ }^{15-18}$

The severe damage produced by normal blood reperfusion could be reduced substantially when the conditions of reperfusion and the composition of the reperfusate were controlled for 30 minutes in a fashion somewhat similar to that applied to regionally ischemic cardiac muscle. ${ }^{15-18}$ The controlled limb reperfusion phase restored oxygen consumption to control levels, avoided tissue edema, limited $\mathrm{CK}$ and potassium release significantly, decreased vascular resistance, restored limb flow to greater than control values, and restored a normal range of motion to the knee joint. ${ }^{4,7,8}$

The findings of the safety and superiority of controlled limb reperfusion led to the current application of these principles in 19 patients with prolonged severe ischemia averaging $26 \pm 6$ hours: The treatment protocol was used despite the presence of ischemic muscle contracture in $53 \%$ of patients. The reversal of ischemic contracture is, to our knowledge, a new finding that irreversible damage has not yet occurred despite the clinical sign of extensive ischemic damage. The only deaths occurred in three of six patients who were in profound cardiogenic shock before the operation (16\% mortality). Sixteen of 19 patients ( $84 \%$ ) were discharged with salvaged limbs, and renal, pulmonary, and cardiac complications did not occur.

No randomization was applied to the patient cohort undergoing controlled limb reperfusion (1) because the experimental data in both crystalloid ${ }^{4-9}$ and blood-perfused models ${ }^{10}$ showed significant improvement of skeletal muscle viability as compared with that obtained with unmodified reperfusion and (2) because of our successful preliminary clinical experience with this technique. ${ }^{50}$

Reperfused skeletal muscle exhibited active oxygen and glucose uptake (see Table IV). We interpret these findings as evidence of active cellular repair during the initial controlled reperfusion phase, which restores some of the cellular hemostatic mechanisms that render jeopardized skeletal muscle able to cope with the subsequent normal blood reperfusion. The marked washout of CK (see Table V) reflects the severe ischemic insult to the skeletal muscle, yet the recovery of function indicates that extensive necrosis had not yet occurred. However, because the sensory and motor functional recovery was not assessed by neurologists, it is possible that some slight alterations might not have been recognized by the discharging physician. Our finding of high CK values and functional recovery of the skeletal muscle is paralleled by reports in cardiac muscle where the mode of reperfusion had no effect on the CK-MB values, whereas a significantly better recovery of regional wall motion could be achieved by an initial treatment of the previously ischemic myocardium during the initial reperfusion phase. ${ }^{16-18}$ Nevertheless, it is likely that the massive release of the large-molecule CK will indicate some cellular death. Additionally, no renal impairment was detected in surviving patients, and slight hyperkalemia did not cause cardiac rhythm disturbances.

The surgical technique applied technology used routinely for delivery of cardioplegic solutions during operations-a heat exchanger, tubing of different caliber to fix the blood/reperfusate ratio, and method of monitoring reperfusion pressure. The 6:1 ratio (blood/ crystalloid solution) was used to limit fluid overload attendant with the crystalloid component of the reperfusate solution, especially in patients with congestive heart failure or cardiogenic shock. Priming of the current system included withdrawal of $400 \mathrm{ml}$ of autogenous blood from the patient, causing slight hypotension. This was reversed readily after controlled limb reperfusion was initiated, and this volume was returned to the patient together with the crystalloid solution. The total volume of reperfusate was approximately $6 \mathrm{~L}(200 \mathrm{ml} / \mathrm{min}$ in 30 minutes $)$, but the crystalloid component was limited to $800 \mathrm{ml}$ by the $6: 1$ blood/reperfusate ratio. This crystalloid infusion did not produce signs of hypervolemia. Future reperfusates will likely include higher ratios of blood to crystalloid solution to reduce the volume of crystalloid solution further.

The reperfusate composition differs slightly from the cardiac reperfusate on which it is based, and which is diluted by the volume of the extracorporeal circuit during cardiac surgery. Modifications were made to limit potential adverse systemic effects, because the effluent returns to the patient by way of the femoral vein. For these reasons, we reduce the volume of tromethamine buffer to decrease the tendency for 
systemic alkalosis, decrease the amount of citratephosphate-dextrose to limit the propensity for systemic hypocalcemia, and lower the concentration of glutamate and aspartate, because amino acids may be associated with systemic vasodilatation. ${ }^{51}$

The selected antioxidant was allopurinol because of its availability and reported use in patients with cardiac disease. ${ }^{52}$ Other antioxidants, especially those having those site-directed effects, may be used subsequently (i.e., superoxide dismutase, catalase, and deferoxamine). We suspect also that subsequent protocols will include interventions that alter other aspects of reperfusion injury. These protocols may incorporate mechanisms of decreasing leukocytes or their adherence and modifications of endothelial function (i.e., L-arginine or nitric oxide) as more is learned about reperfusion injury.

Controlled reperfusate strategy was straightforward and simple to establish in patients requiring cardiac operations, inasmuch as similar principles are used for blood cardioplegic delivery during myocardial protection. Cardiac surgeons and perfusionists are familiar with these principles of organ protection. This study was restricted to patients with impending limb loss as a result of prolonged ischemia. We suspect that future applications may include the prophylactic use of controlled limb reperfusion with prolonged ischemia ( $>3$ hours after femoral vessel cannulation), as well as for extremities exhibiting signs of ischemia during prolonged use of an IABP.

We conclude that clinical application of an experimentally based strategy of controlled limb reperfusion is feasible and useful in the setting of acute limb ischemia in patients having cardiac operations. Its feasibility is enhanced by the fact that the tools for its application are present during most cardiac procedures in which blood cardioplegia is used (i.e., heat exchanger, differential tubing sets, reperfusion cannulas). The encouraging early results in patients with profound ischemia (averaging 26 hours, including contracture) may lead to the prophylactic use of revascularization after prolonged femoral vessel cannulation and limit postreperfusion syndrome further. We hope this report stimulates others to test the applicability of controlled reperfusion in limbs otherwise destined for severe damage. Reproduction of our results by others should decrease the prevalence of postischemic syndrome after acute limb ischemia in patients having cardiac operations, as well as in other patients at risk for this devastating complication of revascularization.

\section{REFERENCES}

1. Blaisdell FW, Stecle M, Allen RE. Management of acute lower extremity arterial ischemia due to embolism and thrombosis. Surgery 1978;84:822-34.

2. Freund U, Romanoff $\mathrm{H}$, Floman Y. Mortality rate following lower limb arterial embolectomy: causative factors. Surgery 1975;77:201-7.

3. Haimovici H. Myopathic-nephrotic-metabolic syndrome associated with massive acute arterial occlusions. J Cardiovasc Surg 1973;14:589-600.

4. Beyersdorf F, Matheis G, Krüger S, et al. Avoiding reperfusion injury after limb revascularization: experimental observations and recommendations for clinical application. J Vasc Surg 1989;9:757-66.

5. Beyersdorf F. Protection of the ischemic skeletal muscle. Thorac Cardiovasc Surg 1991;39:19-28.

6. Beyersdorf F, Unger A, Wildhirt A, et al. Studies of reperfusion injury in skeletal muscle: preserved cellular viability after extended periods of warm ischemia. J Cardiovasc Surg 1991;32:664-76

7. Matheis G, Beyersdorf F, Hanselmann A, et al. Studies of reperfusion injury in skeletal muscle: interaction of osmoticand colloid-osmotic pressure in the initial reperfusate for edema prevention. Cardiovasc Surg 1994;2:725-36.

8. Simon J, Beyersdorf F, Seewald P, Zimmer G, Satter P. Free radical scavengers reduce the ischemic-reperfusion injury in skeletal muscle. Thorac Cardiovasc Surg 1991;39(Suppl):93.

9. Ihnken K, Beyersdorf F, Mitrev Z, et al. Controlled reperfusion reduces reperfusion injury in skeletal muscle after incomplete limb ischemia. Vasc Surg 1994;28:241-60.

10. Mitrev Z, Beyersdorf F, Hallmann R, et al. Studies of reperfusion injury in skeletal muscle: controlled limb reperfusion reduces local and systemic complications after prolonged ischemia - an experimental study using six hours of infrarenal aortic occlusion. Cardiovasc Surg 1994;2:737-48.

11. Korthuis RJ, Granger DN, Townsley MI, Taylor AE. The role of oxygen-derived free radicals in ischemia-induced increases in canine skeletal muscle vascular permeability. Circ Res 1985;57:599-609.

12. Wright JG, Fox D, Kerr JC, Valeri CR, Hobson RW II. Rate of reperfusion blood flow modulates reperfusion injury in skeletal muscle. J Surg Res 1988;44:754-63.

13. Rubin B, Tittley J, Chang G, et al. A clinically applicable method for long-term salvage of postischemic skeletal muscle. J Vasc Surg 1991;13:58-68.

14. Belkin M, LaMorte WL, Wright JG, Hobson RW. The role of leukocytes in pathophysioloy of skeletal muscle ischemic. $\mathbf{J}$ Vasc Surg 1989;10:14-9.

15. Allen BS, Okamoto F, Buckberg GD, et al. Studies of controlled reperfusion after ischemia. XV. Immediate functional recovery after six hours of regional ischemia by careful control of conditions of reperfusion and composition $f$ reperfusate. J Thorac Cardiovasc Surg 1986;92:621-35.

16. Buckberg GD. Studies of controlled repeffusion after ischemia. J Thorac Cardiovasc Surg 1986;92:483-648.

17. Beyersdorf F, Mitrev Z, Sarai K, et al. Changing patterns of patients undergoing emergency surgical revascularization for acute coronary occlusion: importance of myocardial protection techniques. J ThORAC CARDIOvasC SURG 1993;106:13748.

18. Allen BS, Buckberg GD, Fontan FM, et al. Superiority of surgically controlled reperfusion versus percutaneous trans- 
luminal coronary angioplasty in acute coronary occlusion. J Thorac Cardiovasc Surg 1993;105:864-84.

19. Buckberg GD. Antegrade/retrograde blood cardioplegia to ensure cardioplegic distribution: operative techniques and objectives. J Card Surg 1989;4:216-38.

20. Kirklin JW. The sience of cardiac surgery. Eur J Cardiothorac Surg 1990;4:63-71.

21. Fontan F, Madonna F, Naftel DC, Kirklin JW, Blackstone $\mathrm{EH}$, Digerness S. Modifying myocardial management in cardiac surgery: a randomized trial. Eur J Cardiothorac Surg 1992;6:127-36.

22. Beckman CB, Geha AS, Hammond GL, Baue AE. Results and complications of intra-aortic balloon counterpulsation. Ann Thorac Surg 1977;24:550.

23. Goldman BS, Hill TJ, Rosenthai GA, et al. Complications associated with the use of intraaortic balloon pump. Can $\mathbf{J}$ Surg 1982;25:153.

24. Hauser AM, Gordon S, Gangadharan V, et al. Percutaneous intra-aortic balloon counterpulsation: clinical effectiveness and hazards. Chest 1982;82:442.

25. McEnany MT, Kay HR, Buckley MJ, et al. Clinical experience with intra-aortic balloon support in 728 patients. Circulation 1978;58(Pt 2):1128.

26. Goldberg MJ, Rubenfire M, Kantrowitz A, et al. Intra-aortic balloon pump insertion: a randomized study comparing percutaneous and surgical techniques. J Am Coll Cardiol 1987;9:515-23.

27. Gottlieb SO, Brinker JA, Borkon AM, et al. Identification of patients at high risk for complications of intra-aortic balloon counterpulsation: a multivariate risk factor analysis. Am J Cardiol 1984;53:1135-9.

28. Bolooki H. Clinical applications of the intraaortic balloon pump. 2nd ed. New York: Futura, 1984:136-41.

29. Di Lello F, Mullen DC, Flemma RJ, Anderson AJ, Kleinman $\mathrm{LH}$, Werner PH. Results of intraaortic balloon pumping after cardiac surgery: experience with the Percor balloon catheter. Ann Thorac Surg 1988;46:442-6.

30. Lefemine AA, Kosowsky B, Madoff I, Black H, Lewis M. Results and complications of intraaortic balloon pumping in surgical and medical patients. Am J Cardiol 1977;40:416-20.

31. Isner JM, Cohen SR, Virmani R, Lawrinson W, Roberts WC. Complications of the intraaortic balloon counterpulsation device: clinical and morphologic observations in 45 necropsy patients. Am J Cardiol 1980;45:260-8.

32. Alderman JD, Gabliani GI, McCabe $\mathrm{CH}$, et al. Incidence and management of limb ischemia with percutaneous wire-guided intraaortic balloon catheters. J Am Coll Cardiol 1987;9:52430.

33. Kantrowitz A, Wasfie T, Freed PS, Rubenfire M, Wajszczuk W, Schork MA. Intraaortic balloon pumping 1967 through 1982: analysis of complications in 733 patients. Am J Cardiol 1986;57:976-83.

34. Wasfie T, Freed PS, Rubenfire M, et al. Risks associated with intraaortic balloon pumping in patients with and without diabetes mellitus. Am J Cardiol 1988;61:558-62.

35. Iverson LIG, Herfindahl G, Ecker RR, et al. Vascular complications of intraaortic balloon counterpulsation. Am J Surg 1987;54:99-103.

36. Pinkard J, Utley JR, Leyland SA, Morgan M, Johnson H. Relative risk of aortic and femoral insertion of intraaortic balloon pump after coronary artery bypass grafting procedures. J Thorac Cardiovasc Surg 1993;105:721-8.
37. Hazelrigg SR, Auer JE, Seifert PE. Experience in 100 transthoracic balloon pumps. Ann Thorac Surg 1992;54:52832.

38. Satoh H, Kobayashi T, Hiraishi T, et al. New side-holed sheath for intraaortic balloon pumping to maintain limb perfusion. Ann Thorac Surg 1992;54:794-6.

39. Phillips SJ, Tannenbaum M, Zeff RH, lannone LA, Ghali M, Kongtahworn C. Sheathless insertion of percutaneous intraaortic balloon pumps: an alternate method. Ann Thorac Surg 1992;53:162.

40. Tatar H, Çiçek S, Demirkilç U, et al. Vascular complications of intraaortic balloon pumping: unsheathed versus sheathed insertion. Ann Thorac Surg 1993;55:1518-21.

41. Cohn L. Limb ischemia induced by intraaortic balloon pumping [Letter]. J Thorac Cardiovasc Surg 1990;99:566.

42. Opie JC. A simple "solution" worth consideration to combat limb ischemia induced by intraaortic balloon pumping. $J$ Thorac Cardiovasc Surg 1989;98:295-7.

43. Phillips SJ, Zeff RH, Kongtahworn C, et al. Benefits of combined balloon pumping and percutaneous cardiopulmonary bypass. Ann Thorac Surg 1992;54:908-10.

44. Hill JG, Bruhn PS, Cohen SE, et al. Emergent applications of cardiopulmonary support: a multiinstitutional experience. Ann Thorac Surg 1992;54:699-704.

45. The Society of Thoracic Surgeons. The use of extracorporeal circulation for circulatory support during PTCA. J THORAC CARdIOVASC Surg 1990;99:385-6.

46. Labbe R, Lindsay T, Walker P. The extent and distribution of skeletal muscle necrosis after graded periods of complete ischemia. J Vase Surg 1987;6:152-7.

47. Perry MO, Fantini G. Ischemia: profile of an enemyreperfusion injury of skeletal muscle. J Vasc Surg 1987;6: 231-4.

48. Odeh $M$. The role of reperfusion-induced injury in the pathogenesis of the crush syndrome. N Engl J Med 1991;324: 1417-22.

49. Hobson RW II, Lynch TG, Jamil Z, et al. Results of revascularization and amputation in severe lower extremity ischemia: a five-year clinical experience. J Vasc Surg 1985;2: 174-85.

50. Beyersdorf F, Mitrev Z, Eckel L, Sarai K, Satter P. Controlled limb reperfusion as a new surgical technique to reduce postischemic syndrome. J ThoraC CARDIOVASC SuRG 1993; 106:378-80.

51. Amory D, Wagner B, Nicklas W, Zeevalk G. Plasma glutamate and aspartate levels during cardiac surgery. Anesthesiology 1991;75:3A.

52. Coghlan JG, Flitter WD, Clutton SM, et al. Allopurinol pretreatment improves postoperative recovery and reduces lipid peroxidation in patients undergoing coronary artery bypass grafting. J THORAC CARDIOVASC SURG 1994;107:24856.

53. Conneti MC, Murray DM, Wenneker WW. Peripheral arterial emboli. Am J Surg 1984;148:14-9.

54. Cranley JJ, Krause RJ, Strasser ES, Hafner CD. Catheter technique for arterial embolectomy: a seven-year experience. J Cardiovasc Surg 1970;11:44-51.

55. Cranley JJ, Krause RJ, Strasser ES, Hafner CD, Fogarty TJ. Peripheral arterial embolism: changing concepts. Surgery 1964;55:57-63.

56. Darling RC, Austen WG, Linton RR. Arterial embolism. Surg Gynecol Obstet 1967;124:106-14. 
57. Dryjski M, Swedenborg J. Acute ischemia of the extremities in a metropolitean area during one year. J Cardiovasc Surg (Torino) 1984;25:518-22.

58. Eriksson I, Holmberg JT. Analysis of factors affecting limb salvage and mortality after embolectomy. Acta Chir Scand 1975;77:201-7.

59. Hight DW, Nicholas LT, Couch NP. Changing clinical trends in patients with peripheral arterial emboli. Surgery 1976;79: 172-6.

60. Inberg MV, Scheinin TM, Vänttinen EA. Surgical experiences in acute peripheral ischemia: special reference to embolectomy in the aged. J Cardiovasc Surg 1970;11:114-21.

61. Krause RJ, Cranley JJ, Strasser ES, Hafner CD, Fogarty TJ. Further experience with a new embolectomy catheter. Surgery 1966;59:81-6.

62. Levy JF, Butcher HR. Arterial emboli: an analysis of 125 patients. Surgery 1970;68:968-73.
63. MacGowan AL, Mooneram R. A review of 174 patients with arterial embolism. Br J Surg 1973;60:894-8.

64. Müller-Wiefel H, Sello M. Peripheral arterial embolism: experiences with 174 treated extremities. J Cardiovasc Surg 1973;14:312-6.

65. Murie JA, Mathieson M. Arterial embolectomy in the leg: results in a referral hospital. J Cardiovasc Surg 1987;28:184-8

66. Romanoff H, Floman Y. Peripheral arterial embolectomy in the aged. J Cardiovase Surg 1976;17:224-9.

67. Satiani B, Gross WS, Evans WE. Improved limb salvage after arterial embolectomy. Ann Surg 1978;188:153-7.

68. Takolander R, Lannerstad O, Bergqvist D. Peripheral arterial embolectomy, risks and results. Acta Chir Scand 1988; 154:567-72.

69. Thompson JE, Sigler L, Raut PS, Austin DJ, Patman RD. Arterial embolectomy: a 20-year experience with 163 cases. Surgery 1970;67:212-20. 